\title{
Recent advances in the management of Thalassaemia: A Review Update
}

\author{
Sarker NR ${ }^{1}$, Ghosh $\mathrm{AK}^{2}$, Saha $\mathrm{SK}^{3}$, Shariar A
}

\begin{abstract}
The discussion of disease management focuses on the use of transfusion therapy and the newly developed oral iron chelators, deferiprone and deferasirox, especially combination of the chelator drugs. It has been also discussed on splenectomy and pediatrician management of endocrinopathies and cardiac complications. In addition, the use of hematopoietic stem cell transplantation has produced cure rates as high as $97 \%$, and the use of cord blood transplantation as well. Major advances have being made in the discovery of critical modifier genes, such as Myb and especially BCL11A (B cell lymphoma 11A), a master regulator of $\mathrm{HbF}$ (fetal hemoglobin) and hemoglobin switching. Finally, the year 2010 has brought in the first successful experiment of gene therapy in a $\beta$-thalassemia patient, opening up the perspective of a generalized cure for all ß- Thalassaemia patients. (J Shaheed Suhrawardy Med Coll, 2014;6(1):31-37)
\end{abstract}

Key words: Thalassaemia, recent advances, management

Received: January 2014; Revised: March 2014; Accepted: April 2014

\subsection{Introduction}

Thalassemia is a group of autosomal recessive disorders resulting from reduced or absent production of $\beta$-globin chains from the $\beta$-globin locus and these are very heterogeneous at the molecular level ${ }^{1,2}$. The large majority of mutations are simple nucleotide substitutions or deletions or insertions of oligonucleotides leading to frame shift. Rarely the $\beta$-thalassemias are the result of gross gene deletions. Homozygosity for $\beta$-thalassemia usually leads to the severe transfusion dependent phenotype of thalassemia major.

Alfa-Homotetramers in $\beta$-thalassemia are more unstable than $\beta$-homotetramers in alfa- thalassemia and therefore precipitate earlier in the $\mathrm{RBC}$ life span, causing marked RBC damage and severe hemolysis associated with ineffective erythropoiesis (IE) and extra-medullary hemolysis ${ }^{3}$. Ineffective erythropoiesis results in expanded marrow cavities that impinge on normal bone and cause istortion of the cranium, and of facial and long bones. In addition, erythroid activity proliferates in extramedullary hematopoietic sites, causing extensive lymphadenopathy, hepatosplenomegaly and extra-medullary tumors ${ }^{4}$. Over the last 3 decades, profound improvements in the management have been observed. The development of regular transfusion therapy and iron chelation has dramatically improved the quality of life. It has transformed thalassemia from a rapidly fatal disease to a chronic disease compatible with prolonged survival. Today, the life expectancy of patients with thalassemia major has increased from 25 years to over 55 years, mainly due to aggressive transfusion support and chelation coupled with patients' compliance with medical treatment ${ }^{5}$.

In developing world, especially Bangladesh, poor availability of proper medical care, safe and adequate red blood cell transfusions together with high cost and poor compliance with chelation therapy remain major obstacles. Since 1982, hematopoietic stem cell transplantation (HSCT) has become an alternative modality of treatment ${ }^{6}$. It is the only available procedure that may lead to cure. Recently, it has also been demonstrated that cord blood is as effective as, and possibly safer than, bone marrow for transplantation for paediatric patients. On the other hand

1. Dr. Nihar Ranjan Sarker, Associate Professor, Department of Paediatrics, Shaheed Suhrawardy Medical College, Dhaka

2. Dr, Ashis Kumar Ghosh, Medical Officer, Secretariat Clinic, Dhaka

3. Dr. Santosh Kumar Saha, Junior Consultant, Department of Paediatricsics, National Center for Control of Rheumatic Fever \& Heart Disease, Dhaka

4. Dr. Abdullah Shahriar, Assistant Professor, Department of Pediatric Cardiology, National Institute of Cardiovascular Diseases, Dhaka

Correspondence

Dr. Nihar Ranjan Sarker, Associate Professor, Department of Paediatrics, Shaheed Suhrawardy Medical College, Sher-E-Bangla Nagar, Dhaka, Bangladesh; Email: sarkernihar@gmail.com; Cell no.: +8801711611174

Conflict of Interest: None

Contribution to Authors: All authors contribute during the preparation of article. 
there were hopes for the corrective gene therapy. None of the procedures are conducted in Bangladesh. Technological development and researches regarding the recent developments of Thalassemia management are not promising in Bangladesh.

\section{Treatment of $\beta$-thalassemia intermedia}

In $\beta$-thalassemia intermidia patients whose ferritin levels are well above $500 \mathrm{~g} / \mathrm{dL}$, monitoring of iron excess using only serum ferritin is insufficient ${ }^{7}$ and we recommend annual assessments of liver iron concentration (LIC) by liver biopsy or by the more recently applied noninvasive $\mathrm{T}^{*}$ magnetic resonance imaging (MRI ${ }^{8}$ Iron chelation therapy is warranted when LIC exceeds $5-7 \mathrm{mg} / \mathrm{g}$ dry weight and to prevent serious endocrine and cardiac complications similar to those seen in $\beta$-thalassemia Major(TM) patients. Monitoring for splenomegaly and hypersplenism is mandatory as a possible indication of the need for splenectomy.

\section{Management of $\beta$-thalassemia major (TM)}

\section{Transfusion therapy}

The decision to initiate a regular transfusion program in a child newly diagnosed with thalassemia must take into account both laboratory and clinical findings. If the child is growing poorly and has developed facial or other bone abnormalities, and/or when $\mathrm{Hb}$ levels are $<7 \mathrm{~g} / \mathrm{dL}$, regular transfusions will be beneficial4. Confounding factors that might aggravate the degree of anemia, including folic acid deficiency and acute febrile illness, blood loss, or coinheritance of glucose-6-phosphate dehydrogenase deficiency, need to be addressed simultaneously with transfusion therapy. Before the first transfusion, patients' $\mathrm{RBCs}$ are typed for $\mathrm{Rh}$ and $\mathrm{ABO}$ antigens. At the same time, cytomegalovirus status should be obtained when there is a possibility of curative stem cell transplantation (SCT). Parents and first-degree relatives should not be blood donors for these candidates. Hepatitis B vaccination is given before transfusion therapy, as is hepatitis A vaccine when age apropriate ${ }^{4,9}$. Transfusions of washed, leukocyte-depleted RBCs are recommended for all the patients to reduce the incidence of febrile and urticarial reactions as well as infectious cytomegalovirus contamination. If they are not available, frozen thawed $\mathrm{RBCs}$ should be administered. Once a pre-transfusion $\mathrm{Hb}$ level $>9-10 \mathrm{~g} / \mathrm{dL}$ is achieved, transfusions are administered monthly in infancy and subsequently at 2- to 4-week intervals ${ }^{10,11}$. In clinically stable patients, $8-15 \mathrm{~mL}$ RBCs per kilogram of body weight can be infused over a span of 1-2 hours at each transfusion event. If $\mathrm{Hb}$ levels are 5 $\mathrm{g} / \mathrm{dL}$ and/or in the presence of heart failure, smaller aliquots of RBCs $(5 \mathrm{~mL} / \mathrm{kg})$ should be administered to prevent volume overload until the $\mathrm{Hb}$ level is gradually increased to $9 \mathrm{~g} / \mathrm{dL}$. A clinical record of all transfusion events should be monitored annually to identify hypersplenism. A record of weight, the amount of blood transfused at each visit, and the pretransfusion $\mathrm{Hb}$ level is needed to calculate the annual transfusion requirement ${ }^{12}$.

\section{Cardiac complications}

Cardiac failure and serious arrhythmias are the major causes of life-threatening morbidity and mortality in ironoverload patients ${ }^{13}$. Before the availability of chelation therapy, cardiac disease was inevitable during the second decade and still occurs in older patients or those who are poorly compliant with chelation therapy ${ }^{14}$. Therefore, cardiac function is monitored annually beginning at 7 or 8 years of age by electrocardiogram, echocardiogram, 24hour Holter monitor, and recently by cardiac T2* MRI, which can detect preclinical cardiac iron accumulation ${ }^{15}$.

\section{Pericarditis}

Thalassemia patients are susceptible to benign pericarditis, possibly caused by viral and mycoplasmal organisms, bacterial or fungal infections, or associated with the engraftment syndrome in post-transplantation thalassemia patients ${ }^{16}$. "Iron-induced" pericardial siderosis has also been postulated as a causative factor ${ }^{17}$. Diagnosis is made by history and physical signs and is confirmed with serial electrocardiograms and chest $\mathrm{x}$-ray and requires hospitalization if they are symptomatic. Pericarditis is best managed with bed rest and aspirin. Steroids may be helpful with engraftment syndrome and iron chelation with hemosiderosis. When a significantly large pericardial effusion is present, the patient should be hospitalized and observed. Pericardiocentesis and diuretics are recommended to prevent cardiac tamponade ${ }^{18}$. Surgical intervention may be necessary if significant pericardial effusions recur.

\section{Splenectomy}

After the initiation of a regular transfusion program from an early age, splenomegaly may be averted, but hypersplenism may nonetheless develop, usually in children between 5 and 10 years of age. The therapeutic rationale for splenectomy, particularly in patients with growth retardation and poor health, is to protect against the development of extramedullary hematopoiesis by improving the $\mathrm{Hb}$ level, decreasing the transfusion requirement, and consequently reducing iron overload (IO) 19,20. Therefore, we recommend splenectomy when the calculated annual transfusion requirement is _ 200 to $220 \mathrm{~mL} \mathrm{RBCs} / \mathrm{kg}$ per year with a hematocrit of $70 \%$ (equal to $250-275 \mathrm{~mL} / \mathrm{kg}$ per year of packed RBCs with a hematocrit of $60 \%)^{21,22}$. The susceptibility to overwhelming infections after splenectomy can be reduced by immunization with pneumococcal and meningococcal vaccines before splenectomy and antimicrobial prophylaxis with penicillin after splenectomy. Fever over $38^{\circ}\left(101^{\circ} \mathrm{F}\right)$ developing in splenectomized patients with no focus of infection requires immediate intravenous broad-spectrum antibiotics. However, before recommending splenectomy, one should bear in mind that, in a recent evaluation of 584 
patients with TI, significantly higher rates of complications were documented in splenectomized patients ${ }^{13}$.

\section{Newer complications}

Newer and previously less often described complications have now been well-recognised. These include hypercoagulable state, osteoporosis, hepatocellular carcinoma, psychosocial problems.

\section{Hyper-coagulable state}

Because improvements in the medical management of patients with TM and TI have resulted in significant prolongation of life, previously undescribed complications are now being seen. These include the existence of a hypercoagulable state, particularly in splenectomized patients with TI who do not receive regular transfusions ${ }^{23,24}$. Prothrombotic hemostatic anomalies, including low levels of coagulation inhibitors, such as protein $\mathrm{C}$ and protein $\mathrm{S}$ as well as thrombocytosis and platelet activation, have also been observed in these patients ${ }^{25,26}$. However, until now, there are no recommendations based on clinical trials regarding if, when, or for whom prophylactic antithrombotic treatment is indicated

\section{Hepatocellular carcinoma}

Hepatocellular carcinoma (HCC) can complicate liver cirrhosis secondary both to iron overload and viral infections. Italians have published 22 cases of HCC in thalassemia major, 15 of them were males and the mean age of diagnosis was $45 \pm 11$ years13. Eighty-six percent were infected by hepatitis-C virus and majority were diagnosed after 1993, suggesting that the problem is becoming more frequent with the aging population of thalassemia patients ${ }^{27}$.

\section{Osteoporosis}

Although RBC transfusions suppress IE, making skeletal abnormalities less common today than in the past, bone health in thalassemia patients must be monitored to identify age-related low bone mass. Nearly $90.0 \%$ of TM patients, including $30.0 \%$ of those younger than 12 years, have low bone mass Z-score $(<2.0) 28$. For this reason, beginning in childhood, yearly studies that include bone mineral density as well as studies of calcium, vitamin D3 metabolism, and thyroid and parathyroid function should be performed. Administration of pamidronate has shown a significant increase in BMD of the lumber spine and it is now recommended that pamidronate at a monthly dose of $30 \mathrm{mg}$ is an effective treatment for thalassaemic osteoporosis $^{29}$. Alternative treatment includes zolendronic acid in the dose of $1 \mathrm{mg}$ as short I.V. infusion once every 3 months.

\section{Psychosocial problems}

With most of thalassemia major patients achieving adolescence, psycho-social support has become an extremely important part of patient and family management. There is a great need of meeting a genetic counselor at regular intervals. Unfortunately, there is no formal programme on this front in Bangladesh

\section{Oral iron chelators}

In cases of ongoing transfusion therapy, with each RBC unit containing $\beta 200 \mathrm{mg}$ of iron, cumulative iron burden is an inevitable consequence. In TI and TM patients, the rate of transfusional and GI tract iron accumulation is generally $0.3-0.6 \mathrm{mg} / \mathrm{kg}$ per day ${ }^{30}$. Increased GI tract iron absorption can result from severe anemia and IE, which down-regulate the synthesis of hepcidin, a protein that controls iron absorption from the GI tract and increases release of recycled iron from macrophages ${ }^{31-32}$. To date, there are 3 major classes of iron chelators: hexadentate (deferoxamine [DFO], Desferal), dentate (deferiprone, L1 [DFP]), and tridentate (deferasirox [DFX], Exjade) (Table-1).

Table 1: Comparison of the 3 leading iron-chelating drugs in the management of thalassemia

\begin{tabular}{|c|c|c|}
\hline Compound & DFO & DFP \\
\hline Molecular weight & Da 657 & Da139 \\
\hline Chelating properties & Hexadentate & Bidentate \\
\hline Recommended dose & $30-60 \mathrm{mg} / \mathrm{kg} /$ day & $75-100 \mathrm{mg} / \mathrm{kg} /$ day \\
\hline Delivery & $\begin{array}{l}\mathrm{SC} \text { or IV } 8-12 \mathrm{~h} \text {, } \\
5-7 \mathrm{~d} / \mathrm{wk}\end{array}$ & Oral 3 times daily \\
\hline Half-life & $8-10 \mathrm{~min}$ & $1.5-4 \mathrm{~h}$ \\
\hline Excretion & $40 \%-60 \%$ fecal & $90 \%$ urinary \\
\hline Adverse effects & $\begin{array}{l}\text { Ocular, auditory } \\
\text { toxicity, growth } \\
\text { retardation, local } \\
\text { reactions, allergy }\end{array}$ & $\begin{array}{l}\text { Gastrointestinal } \\
\text { upset, arthralgia, } \\
\text { neutropenia, } \\
\text { agranulocytosis }\end{array}$ \\
\hline
\end{tabular}

Source: Eliezer A. Rachmilewitz and Patricia J. Giardina. BLOOD, 29 SEPTEMBER 2011_VOLUME 118, NUMBER 13; * Subcutaneous=SC; intravenous $=\mathrm{IV}$

\section{Efficacy of Iron Chelators}

The purpose of an effective iron chelation therapy is to prevent or reduce body iron accumulation. In regularly transfused patients the rate of iron accumulation, originated from destroyed senescent red cells, is $0.3-0.5 \mathrm{mg} / \mathrm{kg} / \mathrm{day}$. Therefore, a chelator should be able to remove at least this amount of iron to minimize the risk of iron-induced toxicity Several studies have shown that DFP, at comparable doses has an efficacy similar to that of DFO, and that iron excretion increases with the dose and with the degree of iron overload33,34. DFP at appropriate doses is able to decrease or stabilize body iron as assessed by sequential serum ferritin or liver iron concentration, despite repeated RBC transfusions ${ }^{35-37}$. Several independent studies have shown that DFP is more effective than DFO in removing cardiac iron, improving cardiac function and reducing mortality for cardiac disease $\mathrm{e}^{38-40}$. The greater efficacy of DFP in removing excess cardiac iron may be due to some pharmacochemical characteristics of DFP, 
such as low molecular weight, neutral charge and lipophilicity, which facilitate myocyte membrane crossing and chelation of intracellular iron 41 .

\section{Deferiprone and Deferoxamine association}

DFP and DFO can be given to the same patient with different regimes: in ombination on the same day, either simultaneously (i.e. DFP given before breakfast, lunch and dinner and DFO infused during the day) or sequentially (i.e. DFP as above and DFO infused overnight), or as alternate treatment (i.e. one or the other chelator is given on different days). Combination therapy is considered an intensive chelation regimen and usually DFP is administered every day, while subcutaneous DFO is given 2 to 7 days/week, according to the severity of iron overload. In patients with heart failure, to reinforce chelation, DFO can be given intravenously $24 \mathrm{~h} /$ day. The potential advantages of the combined chelation are reported in Table 2. Several single case reports and prospective studies have shown that combined intensive chelation is effective in reducing cardiac siderosis and in improving cardiac function in patients with severe heart iron overload and heart failure ${ }^{42-45}$. A randomized, placebocontrolled, double blind study suggested that in comparison to the standard chelation with DFO, combination therapy with DFO and DFP, was able reduce myocardial iron (ratio of change in cardiac T2* geometric means 1.5 in combined therapy vs 1.24 in DFO monotherapy, $\mathrm{P}=0.02)$ and improve LVEF $(2.6 \%$ vs $0.6 \%$ $\mathrm{P}=0.05$ ). In a study from Greece, reversal of endocrine complications, with very intensive combined chelation (DFP $75-100 \mathrm{mg} / \mathrm{kg} /$ day and DFO $20-60 \mathrm{mg} / \mathrm{kg} / \mathrm{day}$ ), has been reported ${ }^{46}$. More recently, in a large long-term (5 years of follow-up), multicenter study, 213 patients were randomized to receive DFO for 4 days/week and DFP for the remaining 3 days, or DFP monotherapy for 7 days $/$ week $^{47}$. In the alternating treatment group serum ferritin showed a significant reduction $(\mathrm{P}=0.005)$ as compared to DFP group. DFO monotherapy versus DFP monotherapy, alternate or combined DFO-DFP regimes, have been evaluated in another long-term multicenter, randomized trial including 265 patients $^{48}$. None of the patients on DFP alone or in combined treatment died, one death occurred with alternate treatment and 10 deaths with DFO treatment.

Table 2: Potential advantages of combination therapy

*Access to different iron pools

* Greater efficacy

*Dose decrease ${ }^{\circledR}$ toxicity decrease

*Chelation of toxic free iron

*Better tolerability and compliance

\section{Deferasirox and Deferoxamine Association}

Preliminary promising results have been obtained with iron balance studies, which evaluated the total (i.e. fecal and urinary) iron excretion, in three patients treated with DFX and DFO in combination ${ }^{49}$. Total iron excretion was synergistic (i.e. higher than the sum of iron excretion obtained with each single drug) in two patients, but less than additive in the third patient, who responded the best to both drugs individually. Alternating treatment with DFO and DFX resulted to be safe and effective in two retrospective studies including a limited number of patients $^{50,51}$.

\section{Cure of Thalassemia: hematopoietic Stem Cell Transplantation (SCT)}

The first curative allogeneic SCT to a thalassemia patient from an human leukocyte antigen (HLA) identical sibling donor was reported in 1982. Since then, $>3000$ successful transplantations have been reported52. The probability of overall event-free survival has been recently reported as high as $89 \%-97 \%$ for patients with no advanced disease and of $80 \%-87 \%$ for patients with advanced disease ${ }^{53}$. There are several risk factors, including hepatomegaly $>2 \mathrm{~cm}$, portal fibrosis, and inadequate iron chelation therapy, that can influence the outcome of SCT. Approximately $10 \%$ of SCT patients are transfusion-free for years, although they experience persistent mixed hematopoietic chimerism ${ }^{54}$. This suggests that only a few engrafted donor cells are sufficient for correction of donor phenotype. Approximately $30 \%$ subsequently reject their grafts ${ }^{55}$. Those who deteriorate and require further transfusion support may benefit from a second transplantation with nonmyeloblative conditioning to restore normal $\mathrm{Hb}$ levels ${ }^{54}$. Another option is to use matched unrelated donor if a matched sibling is not available or when patients are not compliant with conventional therapy.. However, 40\% developed GVHD and a third had chronic GVHD ${ }^{56}$. A few patients who failed the first transplantation underwent a second transplantation.

\section{Cord blood transplantation}

The potential benefits of umbilical cord blood (UCB) treatment are the low risk of viral contamination from a graft, the decreased incidence of acute and chronic GVHD, and easier accessibility. The small size or small number of stem cells in the UBC collection relative to the number required for engraftment are probably the main causes of failure of UCB transplantation; therefore, this procedure is being used mainly in pediatric patients ${ }^{57}$. The use of UCB from unrelated donors has resulted in only $77 \%$ survival and $65 \%$ event-free survival, respectively, in 36 thalassemia patients $^{58}$. The experience with UCB transplantation is encouraging, but additional data are required for definitive conclusions. On the basis of all the available data to date, we think that every patient with a severe form of thalassemia should be offered the option for SCT. Although SCT is the only curative available, its use is still limited in other developing country because of the relatively high cost and the difficulty in identifying suitable donors. In Bangladesh it is not using at all due to available Bone Marrow Transplant center.

Future therapies for Thalassemia Patients 


\section{Fetal $\mathrm{Hb}$ inducers}

For many years, a major therapeutic goal has been to decrease the severity of anemia in Beta-thalassemia patients by the pharmacologic enhancement of the fetal globin gene expression to increase gama-globin chain production that would improve the excess Alfa-chain imbalance. Several drugs, including erythropoietin, demethylating agents, such as 5-azacytidine, and short chain fatty acids, such as butyrate, have been studied individually and in various combinations59. The shortchain fatty acid butyrate was reported to decrease transfusion requirements in transfusion-dependent thalassemia patients for 7 years. Erythropoietin administration is capable of increasing thalassemic erythropoiesis, mainly in patients with TI but also in those with E-ß--thalassemia, without increasing HbF. Patients with low endogenous erythropoietin levels have been reported to respond to the combination of erythropoietin and butyrate. Hydroxyurea (HU), which is very effective in increasing $\mathrm{HbF}$ levels, has been used extensively for many years in patients with sickle cell anemia (SCA). However, the experience in thalassemia is limited.Asubstantial decrease in transfusion requirements and/or an increase in $\mathrm{Hb}$ levels, which may have been correlated with haplotypes, has been reported during a 6-year follow-up of 149 of 163 patients with $\beta$--thalassemia in Iran subsequent to their receiving a dose of $8-12 \mathrm{mg} / \mathrm{kg}$ per day ${ }^{60,61}$. One of the major concerns is possible effects of $\mathrm{HU}$ on fertility, pregnancy or the risk of malignancy. However, the longterm experience with HU in SCA has ruled out these options62. Most recently, decitabine and HQK-1001, new fetal globin inducers that stimulate fetal globin induction through the proximal promoter and also exhibit erythropoietic-stimulatory effects, are being studied59. Another potential strategy is to develop techniques to silence $\mathrm{HbF}$ suppression. Recently, the molecular basis of the $\mathrm{HbF}$ to $\mathrm{HbA}$ switch identified a variation in chromosome 11-encoding locus BCL11A (B cell lymphoma-leukemia 11A) which was found to be associated with the level of $\mathrm{HbF}$ in patients with thalassemia and to be a regulator of gama-globin expression. Knockdown of BCL11A expression resulted in reactivation of $\mathrm{HbF}$ expression, which inversely correlated with the level of $\mathrm{HbF}^{63}$.

\section{Gene Therapy}

Continuous improvements in the traditional care of $\beta$ thalassemia has ameliorated the quality of life and greatly improved the life expectancy ${ }^{64,65}$. Despite these results, until recently a definitive cure could only be achieved with bone marrow transplantation (BMT) from related or unrelated donors. However, BMT is only available for a minority of patients and bears a significant risk of mortality and morbility, especially when the donor is unrelated $^{66}$. In the search for a more general and definitive cure, hematologists have pursued alternative strategies aimed at correcting the defective $\beta$-globin gene by either gene transfer of a normal $\beta$-globin gene or substitution of the defective gene by homologous recombination. Although gene therapy would have been theoretically possible soon after the discovery and cloning of the human globin genes, for many years two main obstacles have hampered the progress in this field ${ }^{67}$. The first obstacle has been the extremely complex regulation of the globin genes that has taken decades to at least partially unravel. The second and equally important obstacle has been the lack of an optimal vector for gene transfer into quiescent hematopoietic stem cells (HSC). Murine B- thalassaemia models have been successfully cured with the use of a retroviral vector (TN39) transferring the human $\beta$-globin gene sequence and its promoter region into murine stem cells of TI and TM mice ${ }^{68,69}$. $\beta$-Globin gene transfer into progenitor hematopoietic cells of humans is also being studied $^{70,71}$. However, concerns regarding gene transfer include the need for improved efficiency of gene delivery and mastery of vector stability, viral titers, nononcogenic insertion, the variable expression of globin genes, and the variable contributions of the $\beta$-thalassemia phenotype and other modifiers to the effectiveness of gene transfer. Gene therapy is a promising approach to curing thalassemia but is still in the early investigational phase trials

\section{Prevention}

Although, it is not a part of this write up, it is important to stress that the most important advance in the field of thalassemia is its prevention. This has been very successfully achieved in Mediterranean countries i.e., Italy, Greece, Cyprus and Sardinia. There are four important aspects of prevention like Awareness, detection of carrier, effective counseling and prenatal diagnosis. Over last two decades, the programme has been successfully implicated in major cities of India. However, the desired goal of zero birth rate of thalassaemia has remained a distant goal. Bangladesh needs such programme to prevent thalassaemia and to reach the desired goal. However, in the absence of a national thalassemia prevention programme, this still remains a difficult but extremely desirable goal.

\section{References}

1. Wheatherall DJ, Clegg JB. The Thalassemia Syndromes. 4th Ed. 2001 Blackwell Science Ltd

2. Cao A, Galanello R. Beta-Thalassemia. In: Pagon RA, Bird TC, Dolan CR, Stephens K, editors. Gene Reviews [Internet]. Seattle (WA): University of Washington, Seattle; 1993-2000 [updated on: 2010]

3. Rund D, Rachmilewitz E. Beta-thalassemia. N Engl J Med 2005;353:1135-1146

4. Giardina P, Forget B. Thalassemia syndromes. In: Hoffman R, Benz E, Shattil S, et al, eds. Hematology: Basic Principles and Practice (5th ed). Philadelphia, PA: Churchill Livingstone; 2008:535-563

5. Cunningham MJ, Macklin EA, Newfeld EJ, Cohen AR. Complications of â- thalassaemia major in North America. Blood 2004; 104:34-39

6. Erer B, Lucarelli G. Bone marrow transplantation in thalassaemia. Turk J Hematol 1999;16:147-159

7. Borgna-Pignatti C. Modern treatment of thalassaemia intermedia. $\mathrm{Br} \mathrm{J}$ Haematol. 2007;138: 291-304 
8. Wood JC, Enriquez C, Ghugre N, et al. MRI R2 and R2* mapping accurately estimates hepatic iron concentration in transfusion-dependent thalassemia and sickle cell disease patients. Blood. 2005;106:1460-1465

9. Di Marco V, Capra M, Angelucci E, et al. Management of chronic viral hepatitis in patients with thalassemia: recommendations from an international panel. Blood. 2010;116:2875-2883

10. Piomelli S, Graziano J, Karpatkin M, et al. Chelation therapy, transfusion requirement, and iron balance in young thalassemic patients. Ann N Y Acad Sci. 1980;344:409-417

11. Piomelli S, Hart D, Graziano J, et al. Current strategies in the management of Cooley's anemia. Ann N Y Acad Sci. 1985;445:256-267

12. Cohen AR, Glimm E, Porter JB. Effect of transfusional iron intake on response to chelation therapy in beta-thalassemia major. Blood. 2008; 111:583-587

13. Modell B, Khan M, Darlison M. Survival in betathalassaemia major in the UK: data from the UK Thalassaemia Register. Lancet. 2000;355: 2051-2052

14. Ehlers KH, Giardina PJ, Lesser ML, Engle MA, Hilgartner MW. Prolonged survival in patients with beta-thalassemia major treated with deferoxamine. J Pediatr. 1991;118:540-545

15. Kirk P, Roughton M, Porter JB, et al. Cardiac T2* magnetic resonance for prediction of cardiac complications in thalassemia major. Circulation 2009;120:1961-1968

16. Pakakasama S, Wanitkun S, Hongeng S. Pericarditis occurring with engraftment syndrome in a thalassemic patient. Bone Marrow Transplant. 2004;34:819-820

17. Engle MA, Erlandson M, Smith CH. Late cardiac complications of chronic, severe, refractory anemia with hemochromatosis. Circulation. 1964;30:698-705

18. Angelucci E, Mariotti E, Lucarelli G, et al. Sudden cardiac tamponade after chemotherapy for marrow transplantation in thalassaemia. Lancet. 1992; 339:287-289

19. Ataga KI, Cappellini MD, Rachmilewitz EA. Betathalassaemia and sickle cell anaemia as paradigms of hypercoagulability. Br J Haematol. 2007; 139:3-13

20. Eldor A, Rachmilewitz EA. The hypercoagulable state in thalassemia. Blood. 2002;99:36-43

21. Ruf A, Pick M, Deutsch V, et al. In-vivo platelet activation correlates with red cell anionic phospholipid exposure in patients with betathalassaemia major. Br J Haematol. 1997;98:51-56

22. Taher A, Isma'eel H, Mehio G, et al. Prevalence of thromboembolic events among 8860 patients with thalassaemia major and intermedia in the Mediterranean area and Iran. Thromb Haemost. 2006;96:488-491

23. Borgna-Pignatti C, Vergine G, Lombardo $T$ et al. Hepatocellular carcinoma in the thal syndromes. Br J Haematol 2004;124:114-117

24. Vogiatzi MG, Macklin EA, Fung EB, et al. Bone disease in thalassemia: a frequent and still unresolved problem. J Bone Miner Res. 2009;24:543-557

25. Voskardou E, Terpos E, Spina G, Palermos J, Rahemtulla A, Loutradi A et al. Pamidronate is an effective treatment for osteoporosis in patients with beta thalassaemia. Br J Haematol 2003; 123: 730-737

26. Engelhard D, Cividalli G, Rachmilewitz EA. Splenectomy in homozygous beta thalassaemia: a retrospective study of 30 patients. $\mathrm{Br} \mathrm{J}$ Haematol. 1975;31:391-403

27. Cohen A, Gayer R, Mizanin J. Long-term effect of splenectomy on transfusion requirements in thalassemia major. Am J Hematol. 1989;30: 254-256

28. Graziano JH, Piomelli S, Hilgartner M, et al. Chelation therapy in beta-thalassemia major: III. The role of splenectomy in achieving iron balance. J Pediatr. 1981;99:695-699

29. Odame I, Rund D. Evidence-based treatment of thalassemia major. In: Crowther M, Ginsberg J, Schunemann H, Meyer R, Lottenberg R, eds.
Evidence- Based Hematology. Boston, MA: Blackwell; 2008:251-259 30. Pippard M. Iron chelation therapy in the treatment of iron overload. In: Bergeron R, Brittenham G, eds. The Development of Iron Chelators for Clinical Use. Boca Raton, FL: CRC Press; 1994:57- 74

31. Tanno T, Bhanu NV, Oneal PA, et al. High levels of GDF15 in thalassemia suppress expression of the iron regulatory protein hepcidin. Nat Med. 2007;13:1096-1101

32. Gardenghi S, Marongiu MF, Ramos P, et al. Ineffective erythropoiesis in beta thalassemia is characterized by increased iron absorption mediated by down regulation of hepcidin and up regulation of ferroportin. Blood. 2007;109:5027-5035

33. Al-Refaie FN, Sheppard LN, Nortey P, et al. Pharmacokinetics of the oral iron chelator deferiprone (L1) in patients with iron overload. Br J Haematol 1995;89:403-8

34. Collins AF, Fassos FF, Stobie S, et al. Ironbalance and dose-response studies of the oral iron chelator 1,2-dimethyl-3-hydroxypyrid- 4-one (L1) in iron-loaded patients with sickle cell disease. Blood 1994; 83:2329-33

35. Hoffbrand AV, Cohen A, Hershko C. Role of deferiprone in chelation therapy for transfusional iron overload. Blood 2003; 102:17-24

36. Olivieri NF, Koren G, Hermann C, et al. Comparison of oral iron chelator L1 and desferrioxamine in iron-loaded patients. Lancet 1990;336:1275-9

37. Maggio A, D'Amico G, Morabito A, et al. Deferiprone versus deferoxamine in patients with thalassemia major: a randomized clinical trial. Blood Cells Mol Dis 2002;28:196-208

38. Anderson LJ, Wonke B, Prescott E, et al. Comparison of effects of oral deferiprone and subcutaneous desferrioxamine on myocardial iron concentrations and ventricular function in beta-thalassaemia. The Lancet 2002;360:516-20

39. Piga A, Gaglioti C, Fogliacco E, Tricta F. Comparative effects of deferiprone and deferoxamine on survival and cardiac disease in patients with thalassemia major: a retrospective analysis. Haematol 2003;88:48996

40. Borgna-Pignatti C, Cappellini MD, De Stefano P, et al. Cardiac morbidity and mortality in deferoxamine- or deferiprone-treated patients with thalassemia major. Blood 2006;107:3733-7

41. Hider RC, Liu ZD. Emerging understanding of the advantage of small molecules such as hydroxypyridinones in the treatment of iron overload. Curr Med Chem 2003;10:1051-64

42. Wu KH, Chang JS, Tsai CH, Peng CT. Combined therapy with deferiprone and desferrioxamine successfully regresses severe heart failure in patients with betathalassemia major. Ann Hematol 2004;83:471-3

43. Porcu M, Landis N, Salis S, et al. Effects of combined deferiprone and desferrioxamine iron chelating therapy in beta-thalassemia major endstage heart failure A case report. Europ J Heart Fail 2007;9: 320-2

44. Fabio G, Minonzio F, Delbini P, et al. Reversal of cardiac complications by deferiprone and deferoxamine combination therapy in a patient affected by a severe type of juvenile hemochromatosis $(\mathrm{JH})$. Blood 2007;109:362-4

45. Tanner MA, Galanello R, Dessi C, et al. Combined chelation therapy in thalassemia major for the treatment of severe myocardial siderosis with left ventricular dysfunction. J Cardiovasc Magn Reson 2008;10:12

46. Farmaki K, Tzoumari I, Pappa C, et al. Normalisation of total body iron load with very intensive combined chelation reverses cardiac and endocrine complications of thalassaemia major. Br J Haematol 2010; 148:466-75

47. Hongeng S, Pakakasama S, Chuansumrit A, et al. Outcomes of transplantation with related and unrelated donor stem cells in children with severe thalassemia. Biol Blood Marrow Transplant. 2006;12:683-687 48. Gaziev J, Sodani P, Lucarelli G, et al. Second hematopoietic SCT in patients with thalassemia recurrence following rejection of the first graft. 
Bone Marrow Transplant. 2008;42:397-404

49. Galanello R, Agus A, Campus S, et al.Combined iron chelation therapy. Ann N Y Acad Sci 2010;1202:79-86

50. Jetsrisuparb A, Komvilaisak P, Wiangnon S, Jetsrisuparb C. Retrospective study on the combination of desferrioxamine and deferasirox for treatment of iron-overloaded thalassemic patients: first evidence of more than 2 years. J Pediatr Hematol Oncol 2010;32:400-3

51. Balocco M, Carrara P, Pinto V, Forni GL. Daily alternating deferasirox and deferiprone therapy for "hard-to-chelate" beta-thalassemia major patients. Am J Hematol2010; 85:460-1

52. Angelucci E, Baronciani D. Allogeneic stem cell transplantation for thalassemia major. Haematologica. 2008;93:1780-1784

53. Lucarelli G, Gaziev J. Advances in the allogeneic transplantation for thalassemia. Blood Rev. 2008; 22:53-63

54. Gaziev J, Sodani P, Polchi P, et al. Bone marrow transplantation in adults with thalassemia: treatment and long-term follow-up. Ann N Y Acad Sci. 2005;1054:196-205

55. Andreani M, Nesci S, Lucarelli G, et al. Long-term survival of exthalassemic patients with persistent mixed chimerism after bone marrow transplantation. Bone Marrow Transplant. 2000;25:401- 404

56. La Nasa G, Caocci G, Argiolu F, et al. Unrelated donor stem cell transplantation in adult patients with thalassemia. Bone Marrow Transplantation. 2006;36:971-975

57. Gaziev J, Sodani P, Lucarelli G, et al. Second hematopoietic SCT in patients with thalassemia recurrence following rejection of the first graft. Bone Marrow Transplant. 2008;42:397-404

58. Boncimino A, Bertaina A, Locatelli F. Cord blood transplantation in patients with hemoglobinopathies. Transfus Apher Sci. 2010;42:277-281

59. Giardina P, Forget B. Thalassemia syndromes. In: Hoffman R, Benz E, Shattil S, et al, eds. Hematology:Basic Principles and Practice (5th ed).
Philadelphia, PA: Churchill Livingstone; 2008:535-563

60. Dixit A, Chatterjee TC, Mishra P, et al. Hydroxyurea in thalassemia intermedia: a promising therapy. Ann Hematol. 2005;84:441-446

61. Karimi M, Darzi H, Yavarian M. Haematologic and clinical responses of thelassemia intermedia patients to hydroxyurea during 6 years of therapy in Iran. J Pediatr Hematol Oncol. 2005;27:380- 385

62. Ware RE. How I use hydroxyurea to treat young patients with sickle cell anemia. Blood. 2010; 115:5300-5311

63. Sankaran VG, Xu J, Orkin SH. Advances in the understanding of haemoglobin switching. Br J Haematol. 2010;149:181-194

64. Borgna-Pignatti C, Cappellini MD, De Stefano P, et al. Survival and complications in thalassemia. Ann N Y Acad Sci 2005;1054:40-7

65. Cao A. Quality of life and survival of patients with beta-thalassemia major. Haematol 2004;89: 1157-9

66. La Nasa G, Argiolu F, Giardini C, et al. Unrelated bone marrow transplantation for beta-thalassemia patients: The experience of the Italian Bone Marrow Transplant Group. Ann N Y Acad Sci 2005; 1054:186-95

67. Moi P, Sadelain M. Towards the genetic treatment of beta-thalassemia: new disease models, new vectors, new cells. Haematol 2008;93:325-30 68. Rivella S, May C, Chadburn A, et al. A novel murine model of Cooley anemia and its rescue by lentiviral-mediated human beta-globin gene transfer. Blood. 2003;101:2932-2939

69. May C, Rivella S, Callegari J. Therapeutic haemoglobin synthesis in beta-thalassaemic mice expressing lentivirus-encoded human betaglobin. Nature. 2000;406:82-86

70. Breda L, Kleinert D, Casu C, et al. A preclinical approach for gene therapy of beta-thalassemia. Ann N Y Acad Sci. 2010;1202:134-140

71. Breda L, Rivella S. Gene therapy in thalassemia and hemoglobinopathies. Mediterr J Hematol Infect Dis. 2009;1:1 